\title{
Complete hemispheric exposure vs. superior sagittal sinus sparing craniectomy: incidence of shear-bleeding and shunt-dependency
}

\author{
Martin Vychopen $^{1}$ D $\cdot$ Matthias Schneider ${ }^{1} \cdot$ Valeri Borger $^{1} \cdot$ Patrick Schuss $^{1} \cdot$ Charlotte Behning $^{2} \cdot$ Hartmut Vatter $^{1} \cdot$ \\ Erdem Güresir ${ }^{1}$
}

Received: 25 January 2021 / Accepted: 1 September 2021 / Published online: 4 October 2021

(c) The Author(s) 2021

\begin{abstract}
Purpose Decompressive hemicraniectomy (DC) has been established as a standard therapeutical procedure for raised intracranial pressure. However, the size of the DC remains unspecified. The aim of this study was to analyze size related complications following DC.

Methods Between 2013 and 2019, 306 patients underwent DC for elevated intracranial pressure at author's institution. Anteroposterior and craniocaudal DC size was measured according to the postoperative CT scans. Patients were divided into two groups with (1) exposed superior sagittal sinus (SE) and (2) without superior sagittal sinus exposure (SC). DC related complications e.g. shear-bleeding at the margins of craniectomy and secondary hydrocephalus were evaluated and compared. Results Craniectomy size according to anteroposterior diameter and surface was larger in the SE group; $14.1 \pm 1 \mathrm{~cm}$ vs. $13.7 \pm 1.2 \mathrm{~cm}, p=0.003$, resp. $222.5 \pm 40 \mathrm{~cm}^{2}$ vs. $182.7 \pm 36.9 \mathrm{~cm}^{2}, p<0.0001$. The SE group had significantly lower rates of shear-bleeding: $20 / 176$ patients; $(11 \%)$, compared to patients of the SC group; 36/130 patients $(27 \%), p=0.0003$, OR $2.9,95 \%$ CI $1.6-5.5$.

There was no significant difference in the incidence of shunt-dependent hydrocephalus; $19 / 130$ patients (14.6\%) vs. $24 / 176$ patients $(13.6 \%), p=0.9$.

Conclusions Complete hemispheric exposure in terms of DC with SE was associated with significantly lower levels of iatrogenic shear-bleedings compared to a SC-surgical regime. Although we did not find significant outcome difference, our findings suggest aggressive craniectomy regimes including SE to constitute the surgical treatment strategy of choice for malignant intracranial pressure.
\end{abstract}

Keywords Decompressive hemicraniectomy $\cdot$ Size $\cdot$ Shear-bleeding

\section{Backround}

Decompressive hemicraniectomy (DC) is an established surgical method for treatment of raised intracranial pressure caused by cerebral infarction (CI) [1], traumatic brain injury (TBI) [2], subarachnoid hemorrhage (SAH) [3] and intracerebral hemorrhage ( $\mathrm{ICH})$ [4]. An adequate anteroposterior diameter of DC has already been described to be at least $12 \mathrm{~cm}$, accompanied with adequate temporobasal decompression [5, 6]. Contrary to AP diameter [7]; the

\section{Hartmut Vatter}

hartmut.vatter@ukbonn.de

Erdem Güresir

erdem.gueresir@ukbonn.de

matthias.schneider@ukbonn.de

Valeri Borger

valeri.borger@ukbonn.de

Patrick Schuss

patrick.schuss@ukbonn.de

Charlotte Behning

behning@imbie.uni-bonn.de
1 Department of Neurosurgery, University Hospital Bonn, Venusberg Campus 1, 53127 Bonn, Germany

2 Department of Medical Biometry, Informatics and Epidemiology, Universität Bonn, Institut für Medizinische Biometrie, Informatik und Epidemiologie (IMBIE), Bonn, Germany 
optimal craniocaudal diameter remains unspecified. An agressive craniectomy, including maximal decompression with exposure of superior sagittal sinus, might be a risk factor for shunt-dependency. This study aims to analyze the size related complications of two different surgical techniques of DC according to anatomical landmarks: patients undergoing complete hemispheric exposure vs. those without exposure of the superior sagittal sinus (SSS). We mainly focused on the incidence of shunt-dependent hydrocephalus and the incidence of shear-bleeding at the edge of DC.

\section{Methods}

A retrospective single center study of patients undergoing DC from 02/2013 to 10/2019 was performed. The extent of the craniectomy was analyzed using early postoperative CT scans with DICOM Viewer software. We measured the anteroposterior diameter as proposed by Flint et al. [8]. The surface of the craniectomy was calculated using the De Bonis equation [9]. We divided the patients in two groups based on anatomical landmarks: (1) patients with complete exposure of superior sagittal sinus (SE) and (2) patients without exposure of superior sagittal sinus (SC) (Figs. 1 and 2).

\section{Surgical techniques}

The head of the patient is positioned with his head rotated parallel to the floor, the side of the craniectomy pointing upwards. Mayfield skull clamp is used to fix the head. By unilateral decompressive hemicraniectomy, the half of the head is shaved. The incision in the shape of a reverse question mark is starting at the tragus and continuing slightly across the midline. The trauma flap is created [10].

Group 1 (SE) — after exposing the skull, sagittal suture is identified and two burrholes are placed on the sagittal suture, where SSS is expected, determining the medial craniectomy edge. The sagittal sinus was exposed by craniectomy on sagittal suture. Usually, full exposure of the hemisphere including the exposure of the SSS is reached. Duraplasty is not performed.

Group 2 (SC)—after identifying the sagittal suture, the burrholes are placed ipsilateral on the site of the craniectomy, leaving $1-2.5 \mathrm{~cm}$ distance between the edge of the craniectomy and sagittal suture. Both sinus and

Fig. 1 Left-coronar and axial view of the SE group. Rightcoronar and axial view of the $\mathrm{SC}$ group
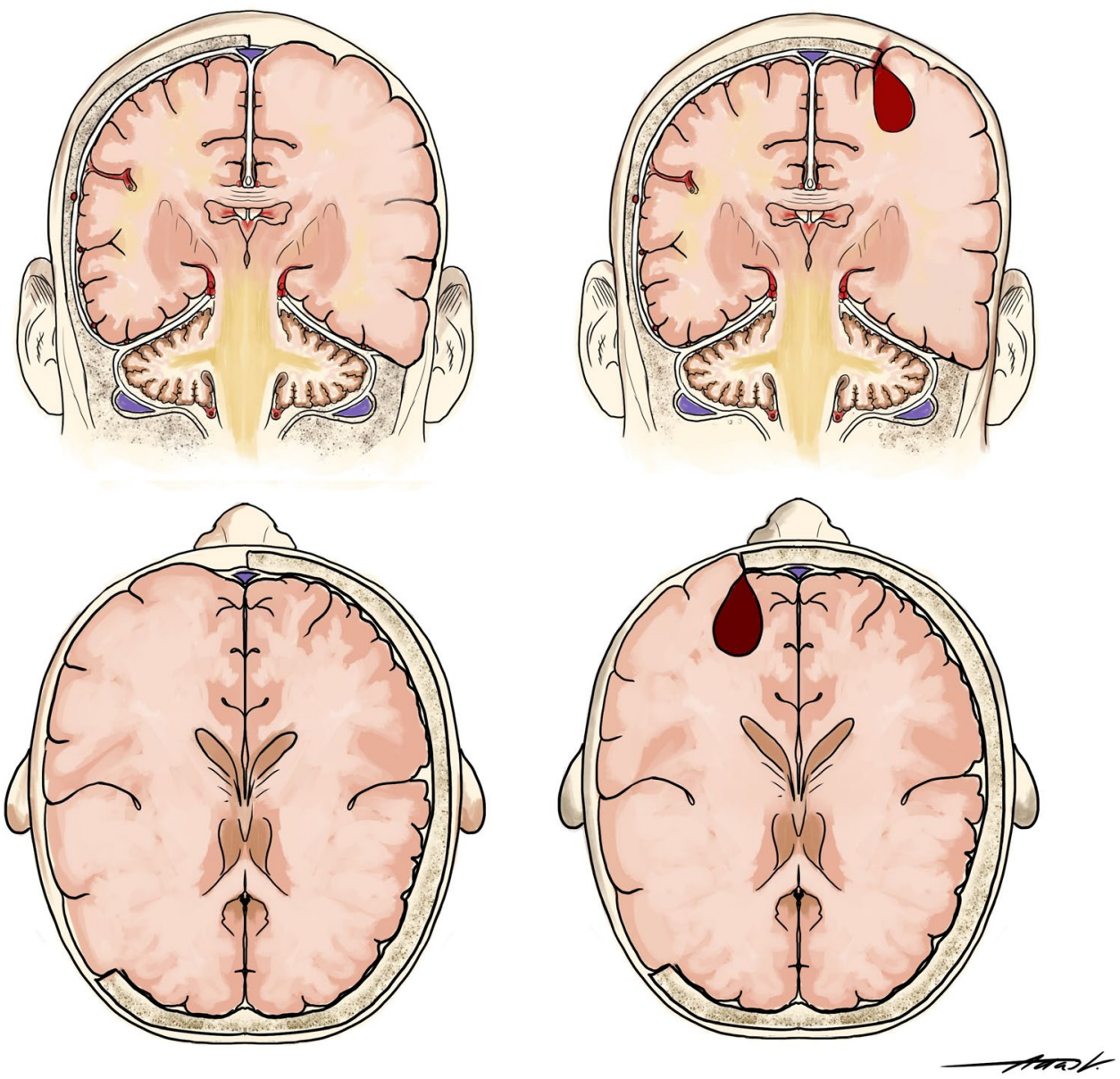
Fig. 2 Left-3D view of SE group. Right-3d view of SC group
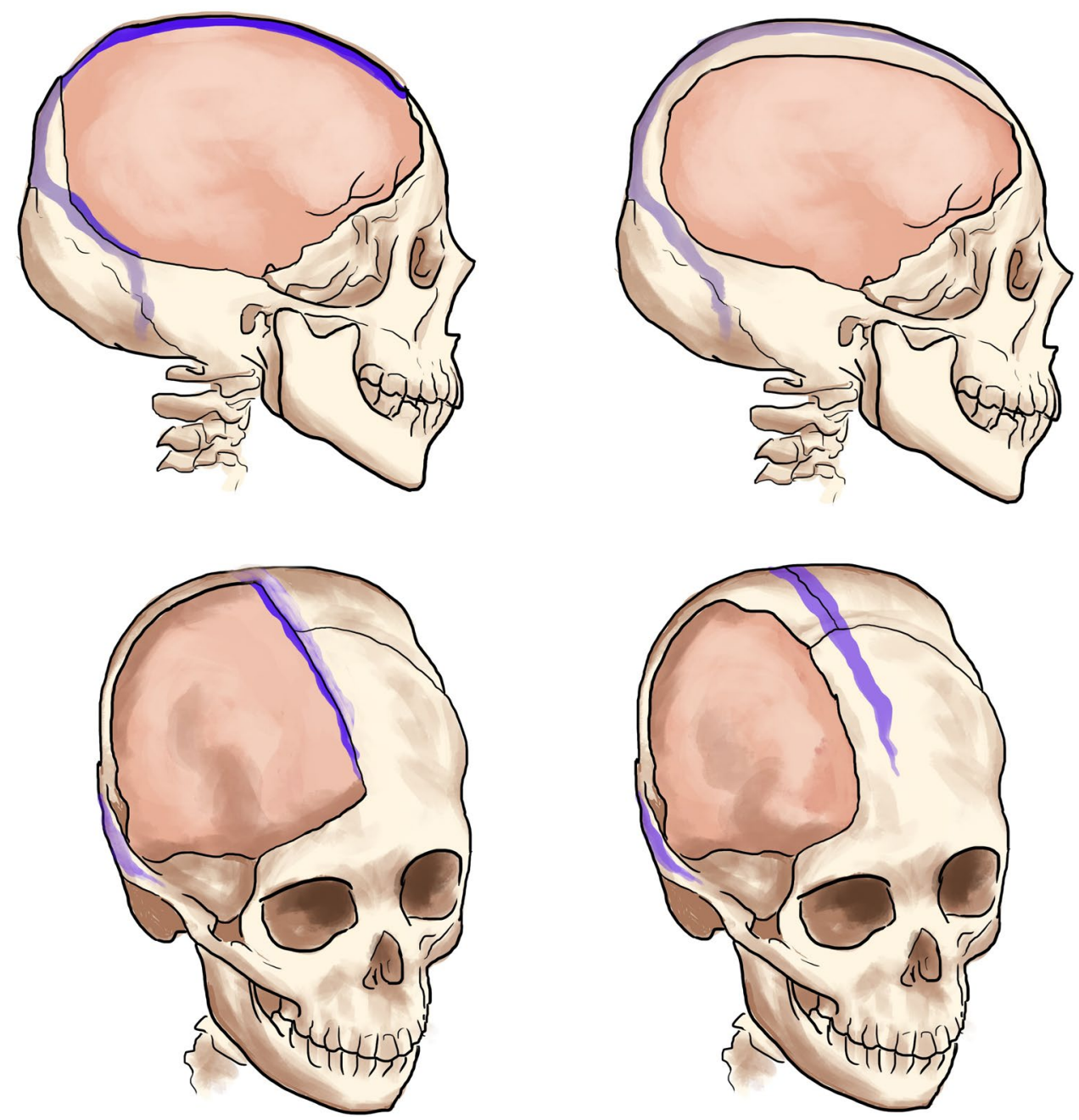

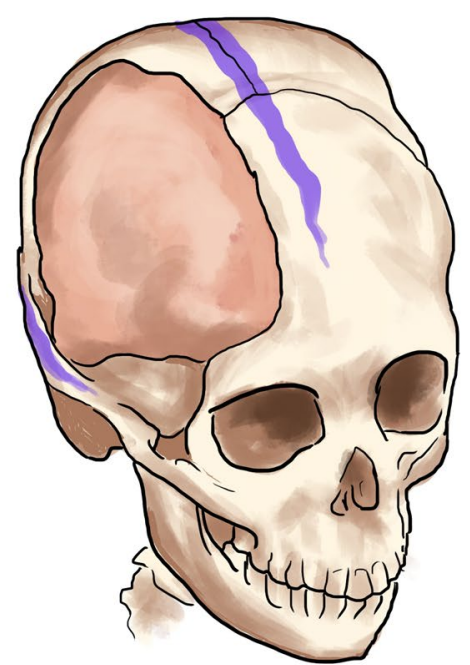

bridging veins are covered with bone. Duraplasty is also not performed.

The sinus exposure was performed according to attending neurosurgeon.

\section{Peri/postoperative complications}

\section{Shear-bleeding}

All available postoperative CT scans were analyzed for the incidence of newly developed intraparenchymal hemorrhage at the edge of the craniectomy (Fig. 3).

\section{Shunt-dependent hydrocephalus}

The focus was given on patients who developed shuntdependent hydrocephalus after DC and underwent secondary shunt implantation.

\section{Further postoperative complications}

We retrospectively analyzed and compared perioperative blood-loss, the need of red blood cell transfusions, wound healing disturbances, operating time, air embolism, sinus thrombosis and intraoperative sinus injury. We divided the outcome of the patients as favorable $(\mathrm{mRS} \leq 3)$ and unfavorable $(\mathrm{mRS}>3)$.

\section{Statistics}

A Fisher's exact test was used to demonstrate the association between the sinus exposure and development of shearbleeding and shunt-dependent hydrocephalus. Values with $p<0.05$ were considered to be significant. Finally, propensity score adjustment was performed to analyze the risk-bleeding risk factors between the groups. 
Fig. 3 Above left-axial CT scan of patient from SE group. Above right-axial CT scan of patient from SC group, the arrow is pointing on shearbleeding. Below left-preoperative CT scan of patient from SC group. Below right-postoperative CT scan with newly developed shear-bleeding

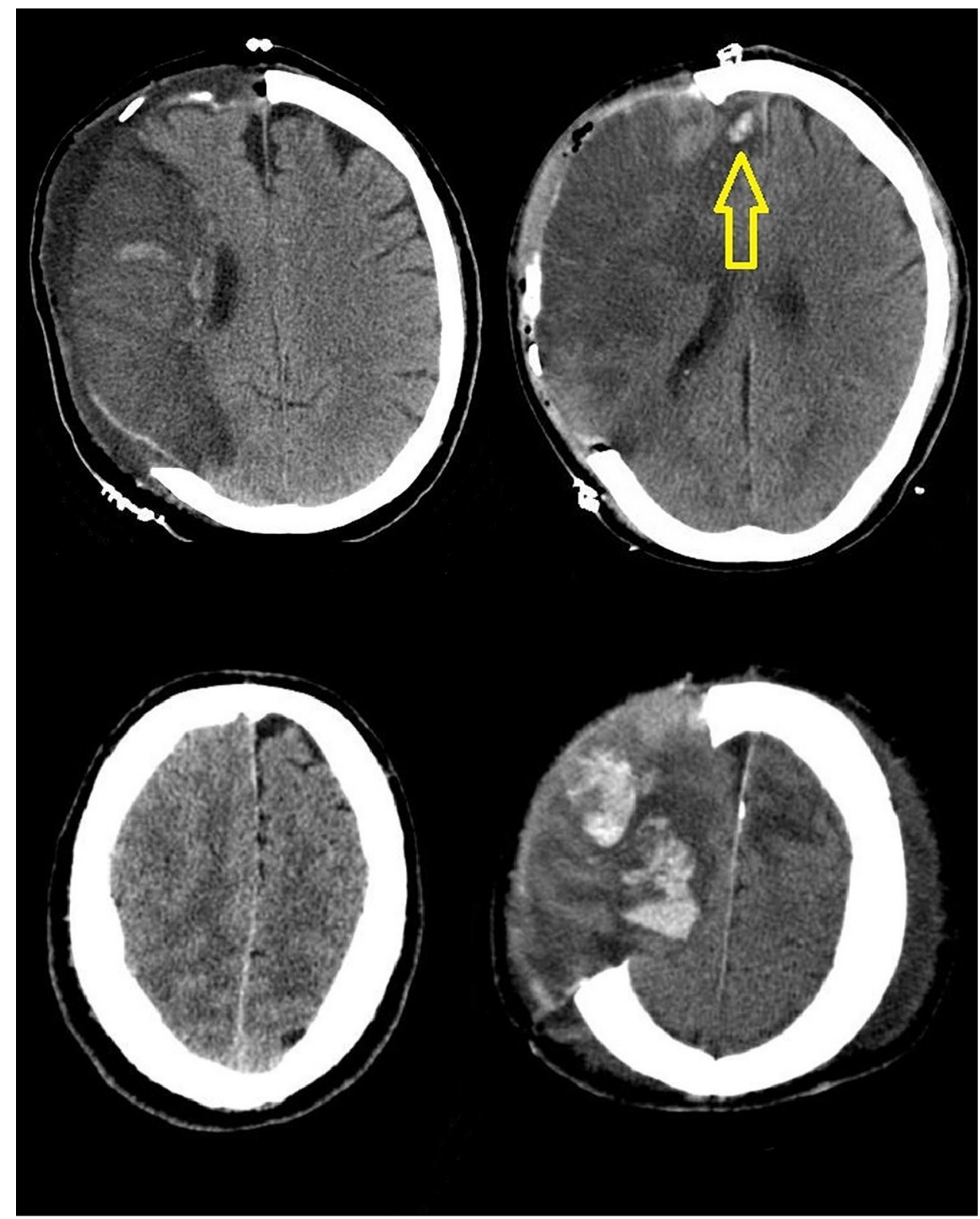

\section{Results}

\section{Patient characteristics}

381 patients underwent DC at our institution between 02/2013 and 10/2019. 75 patients were excluded because of: insufficient postoperative imaging $(n=43)$, bifrontal craniectomy $(n=17)$ and age $<18$ years $(n=15) .306$ patients were included in the analysis, 176 in SE group and 130 in SC group (see Table 1). The underlying diagnosis was TBI $(n=85)$, ICH $(n=68)$, CI $(n=81)$, SAH $(n=47)$ and miscellaneous pathologies including meningitis $(n=4)$, postoperative edema of unclear origin $(n=13)$, sinus thrombosis $(n=4)$, spontaneous subdural hematoma $(n=1)$, bleeding after electrode implantation $(n=1)$, cerebral edema after callosotomy $(n=1)$ and primary cerebral edema of unclear origin $(n=1)$. For details, see Table 1.

\section{Anteroposterior diameter and surface}

Anteroposterior diameter of the DC was overall of $13.7 \mathrm{~cm} \pm 1.2 \mathrm{~cm}$. The AP Diameter was significantly larger in SE Group compared to SC Group; $14.1 \pm 1.1 \mathrm{~cm}$ vs. $13.7 \pm 1.2 \mathrm{~cm}, p=0.003$.

There was a significant difference in surface of the resected bone between both groups; SE Group $222.5 \pm 40.0$ $\mathrm{cm}^{2}$ vs. SC Group $182.7 \pm 36.9 \mathrm{~cm}^{2}, p<0.0001$. For detailed information, see Table 2. 
Table 1 Patient characteristics

\begin{tabular}{ll}
\hline Sex & \\
Male & 171 \\
Female & 135 \\
Underlying pathology & \\
TBI & $85(27.7 \%)$ \\
ICH & $68(22.2 \%)$ \\
CI & $81(26.5 \%)$ \\
SAH & $47(15.4 \%)$ \\
Miscellaneous pathologies & $25(8.1 \%)$ \\
Mean age ( \pm SD) in years & $57.26 \pm 15.54$ \\
Number of patients & 306 \\
SE group & $176(57.5 \%)$ \\
SC group & $130(42.5 \%)$ \\
\hline
\end{tabular}

TBI traumatic brain injury, $I C H$ intracerebral hemorrhage, $C I$ cerebral infarction, $S A H$ subarachnoid hemorrhage, $S D$ standard deviation, $S E$ group sinus exposed group, $S C$ group sinus not exposed group

In exploratory analysis, the craniectomy type seems to be the only statistically significant factor associated with the incidence of shear-bleeding (Table 3).

\section{Shear-bleeding incidence and localization}

20 out of 176 (11\%) patients in SE group had shear-bleeding, whereas, 36 out of 130 (27\%) of the patients in SC group had shear-bleeding; $p=0.0003$, OR 2.9, 95\% CI 1.6-5.5.
Table 3 Multivariate analysis of shear-bleeding risk factors

\begin{tabular}{lll}
\hline & CI 95\% & $p$ value \\
\hline AP-diameter & $0.98-1.01$ & 0.34 \\
Operative time & $0.998-1.01$ & 0.13 \\
Surface & $1.0-1.0$ & 0.53 \\
Type of craniectomy & $0.22-0.85$ & 0.01 \\
\hline
\end{tabular}

AP-diameter anteroposterior diameter

Most of the shear-bleeding lesions were localized near the medial boundary of the craniectomy. The incidence of these medially localized lesions was significantly lower in SE group with $6.8 \%$ vs. $20.8 \%$ in SC group; $p=0.0003$ (Fig. 4).

\section{Underlying diagnosis}

SC was associated with higher incidence of shear-bleeding in all underlying conditions leading to DC. The limitation of this analysis is the low number of patients in each subgroup. See Fig. 5 and Table 4

\section{Shunt-dependency}

43 patients developed secondary drainage-dependent hydrocephalus and underwent a shunt implantation.
Table 2 Sinus exposed vs. sinus covered - group analysis

\begin{tabular}{llll}
\hline & SE group $(n=176)$ & SC group $(n=130)$ & \\
\hline Men:women & $95(53.9 \%): 81(46.1 \%)$ & $80(61.5 \%): 50(38.5 \%)$ & $p=0.18$ \\
INR & $1.2 \pm 0.4$ & $1.1 \pm 0.4$ & $p=1.0$ \\
Platelets $(G / l)$ & $228 \pm 98.5$ & $238 \pm 102.79$ & $p=0.4$ \\
aPTT $(s)$ & $26 \pm 8.5$ & $25 \pm 4.9$ & $p=0.2$ \\
Hemoglobin $(g / d l)$ & $12.4 \pm 2.2$ & $12.6 \pm 2.09$ & $p=0.4$ \\
History of anticoagulants & $43 / 176(24.4 \%)$ & $32 / 130(24.6 \%)$ & \\
GCS at admission & $8 \pm 4.42$ & $8.5 \pm 4.29$ & $p=0.3$ \\
Operative time (min) & $86.3 \pm 26.6$ & $99.3 \pm 31.8$ & $p=0.0001$ \\
AP-diameter & $14.1 \pm 1.1 \mathrm{~cm}$ & $13.19 \pm 1.1 \mathrm{~cm}$ & $p=0.0027$ \\
Surface of DC & $222.50 \pm 40.0 \mathrm{~cm}^{2}$ & $182.7 \pm 36.9 \mathrm{~cm}^{2}$ & $p<0.0001$ \\
Shear-bleeding & $20(11 \%)$ & $36(27 \%)$ & $p=0.0003$ \\
Shunt-dependency & $24(13.6 \%)$ & $19(14.6 \%)$ & $p=0.9$ \\
Wound-healing disturbances & 12 & 7 & $p=0.607$ \\
Blood loss $\leq 500$ ml & $47(26.7 \%)$ & $26(26.7 \%)$ & $p=0.741$ \\
Red blood cell transfusions & $90(51.1 \%)$ & $64(49.2 \%)$ & \\
Shear-bleeding localization & & & $p=0.0001$ \\
Medial DC margin & $11(6.2 \%)$ & $27(20.8 \%)$ & \\
Medial + lateral DC margin & $3(1.7 \%)$ & $2(5.3 \%)$ & \\
Lateral DC margin & $6(3.4 \%)$ & & \\
\hline
\end{tabular}

Italic values indicates statistically significant $p<0.05$ 
Fig. 4 Left-shear-bleeding localization in SE group. Right-shear-bleeding localization in SC group
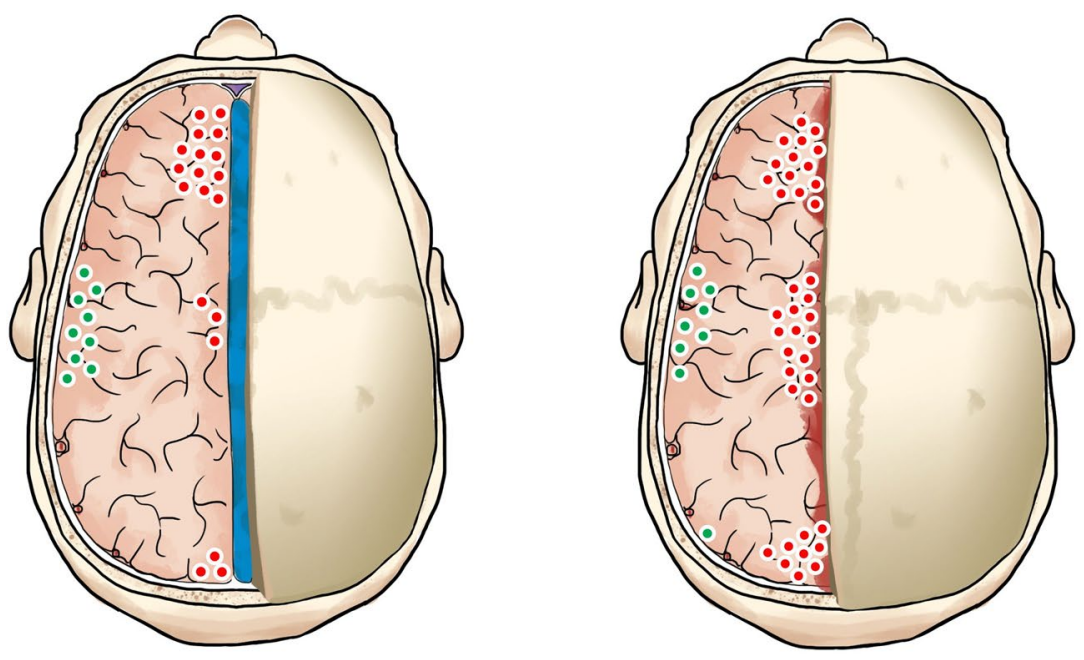

100

Fig. 5 Shear bleeding according to underlying condition

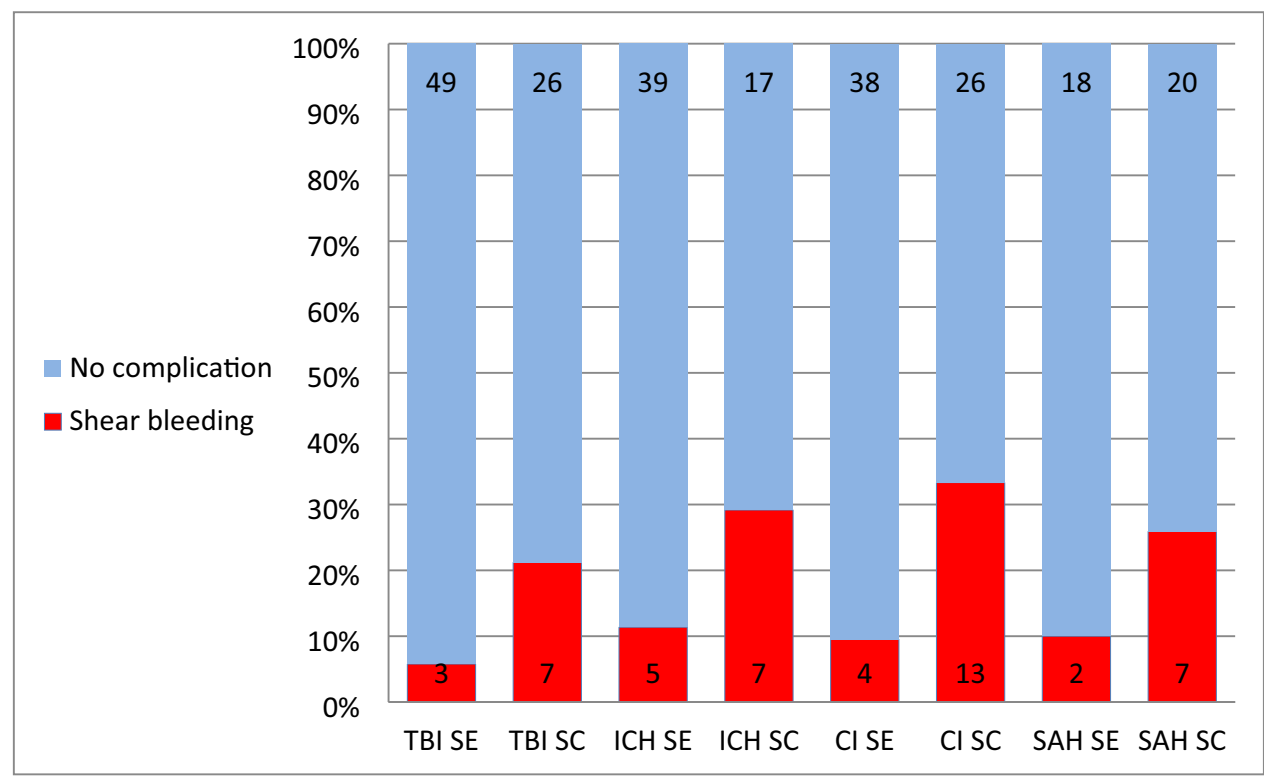

\footnotetext{
TBI - traumatic brain injury

$\mathrm{ICH}$ - intracerebral hemorrhage

CI - cerebral infarction

SAH - subarachnoid hemorrhage

$\mathrm{SE}$ - Sinus exposed

$\mathrm{SC}-$ Sinus covered
}

Shunt-dependency rates did not significantly differ between the two groups: 24 patients $(13.6 \%)$ in SE group vs. 19 patients $(14.6 \%)$ in SC group $(p=0.9)$.

\section{Intraoperative blood-loss}

None of the analyzed groups presented itself with higher intraoperative bleeding volume. The blood loss was lower as $500 \mathrm{ml}$ in $26.7 \%$ of cases.

The red blood cell transfusion rates did not differ between both groups; SE 90/176 (51.1\%) vs. SC 64/130 (49.2\%), $p=0.7$. 
Table 4 Subgroup analysis of complications

\begin{tabular}{lrrrrrrrr}
\hline & TBI SE & TBI SC & ICH SE & ICH SC & CI SE & CI SC & SAH SE & SAH SC \\
\hline No complication & $\mathbf{4 6}$ & $\mathbf{2 3}$ & $\mathbf{3 6}$ & $\mathbf{1 3}$ & $\mathbf{3 7}$ & $\mathbf{2 5}$ & $\mathbf{1 2}$ & $\mathbf{1 6}$ \\
Complications & $\mathbf{6}$ & $\mathbf{1 0}$ & $\mathbf{8}$ & $\mathbf{1 1}$ & $\mathbf{5}$ & $\mathbf{1 4}$ & $\mathbf{8}$ & $\mathbf{1 1}$ \\
Shunt & 3 & 3 & 3 & 4 & 1 & 1 & 6 & 4 \\
Shunt and shear-bleeding & 0 & 1 & 1 & 1 & 0 & 2 & 0 & 2 \\
Shear-bleeding & 3 & 6 & 4 & 6 & 4 & 11 & 2 & 5 \\
\hline
\end{tabular}

Bold values indicates statistically significant $p<0.05$

$T B I$ traumatic brain injury, $I C H$ intracerebral hemorrhage, $C I$ cerebral infarction, $S A H$ subarachnoid hemorrhage, $S E$ sinus exposed, $S C$ sinus covered

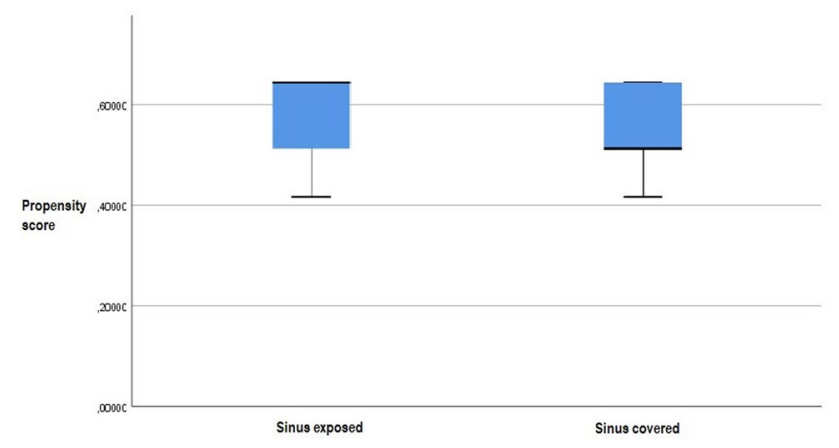

Fig. 6 Propensity score Box-plot, sinus exposed vs. sinus covered

\section{Wound-healing disturbances}

Wound-healing disturbances were observed in 19 cases. Four of them underwent the DC because of CI (2 SE vs. 2 SC), four because of SAH (2 SE vs. 2 SC) eight because of TBI (4 SE vs. $3 \mathrm{SC}$ ) and four because of ICH (4 SE vs. 0 $\mathrm{SC})$. There was no difference between both groups noted, $p=0.6$.

\section{Operative time}

The operative times of the SE group were significantly shorter compared to the SC group (SE $86.3 \pm 26.6$ min vs. SC $99.3 \pm 31.8 \mathrm{~min}, \mathrm{CI} 95 \% 6.4-19.6, p=0.0001)$. However, the mean difference was $13 \mathrm{~min}$.

\section{Propensity score adjustment}

Propensity score analysis was performed to evaluate the shear-bleeding risk-factor. According to risk factors published by Hanko et al. [11] we included platelet count, INR, $\mathrm{Hb}$, blood-thinners history and underlying pathology. Propensity scores were $0.59 \pm 0.09$ in the SE Group and $0.55 \pm 0.09$ in the SC Group; $p=0.003$ ). The difference between the groups was observed in the distribution of $C I$ $(p=0.043, C I 0.34-0.99)$ and $S A H(p=0.005, C I 0.20-0.75)$ (Fig. 6).
Table 5 Propensity score vs. type of craniectomy analysis

\begin{tabular}{lcl}
\hline & $p$ value & CI 95\% \\
\hline Type of craniectomy & $<\mathbf{0 . 0 0 0 1}$ & $\mathbf{0 . 1 8 - 0 . 6 1}$ \\
Propensity score & $\mathbf{0 . 9 6}$ & $\mathbf{0 . 0 3 - 3 0 . 3 8}$ \\
\hline
\end{tabular}

Bold italic values indicate statistically significant $p<0.05$

CI confidence interval

In the logistic regression with shear-bleeding as dependent variable, the type of craniectomy as well as the propensity score as independent variables. The type of craniectomy remained significantly associated (Table 5).

\section{Clinical outcome (mRS) 6 months postoperatively}

Favorable outcome was observed by $37 / 176(21.0 \%)$ patients in SE group vs. 30/130 in SC group (23.0\%); $p=0.9$. The analysis of the shear-bleeding subgroup showed favorable outcome by 6/20 patients in SE group (30.0\%) vs. 7/36 patients (19.4\%) in SC group.

\section{Discussion}

We retrospectively analyzed patients that had undergone DC in the course of surgical treatment of pathologically raised intracranial pressure at our institution. We compared two surgical approaches of craniectomies with or without exposure of SSS. The SE group showed significantly lower incidence of shear-bleeding. No difference in shunt-dependency was noted between the groups.

\section{Size-anteroposterior diameter and surface of the DC}

The idea of a positive correlation between size and ICP reduction was already demonstrated experimentally [12]. The size of the DC seems to play a crucial role in mortality [13] and outcome [14] by patients with TBI. The anteroposterior diameter of all DCs in our cohort exceeded the $12 \mathrm{~cm}$ proposed by Wagner et al. [5] as sufficient decompression. 
As we expected, the SE group showed significantly higher anteroposterior decompression.

Both groups overreached the DC surface size published either by De Bonis $\left(162 \mathrm{~cm}^{2}\right)$ [15] and Sturiale $\left(168 \mathrm{~cm}^{2}\right)$ [16] or by Reid $\left(119 \mathrm{~cm}^{2}\right)$ [17].

\section{Shear-bleeding}

Our study confirmed the experimentally discussed association between the parenchyma injury around the craniectomy edges and the size of the DC [18]. We observed higher rates of shear-bleedings localized medially in the SC group. As demonstrated above, centrally localized shear-bleeding can lead to severe clinical symptomatic.

Compared to Wagner et al. [5], we did not include the patients with the increased size of ICH.

We did not classify the progression of already presented $\mathrm{ICH}$ as a shear-bleeding, but as "relief-effect" bleeding. "Relief-effect" bleeding is not a complication corresponding directly to the size of the DC. It is rather associated with the procedure itself as a result of sudden pressure relief during the DC, loss of tamponade effect and rapid expansion of the cerebral parenchyma [7, 19].

As expected, the SE group showed significantly lower incidence of the shear-bleeding than the SC group.

\section{Shunt-dependency}

DC has been previously reported to be a risk factor for hydrocephalus development. The idea suggested by De Bonis et al. [15] that the incidence of shunt-dependent hydrocephalus increases if the SSS and the bridging veins are exposed has not been confirmed in our cohort. We observed the same distribution of shunt-dependency among both groups regardless of the DC size. The incidence of shunt implantation corresponds to results already reported by other authors reaching from 14.8 to $22.5 \%$ according to underlying pathology [14, $20,21]$.

The proposed mechanism of hydrocephalus by DCs going near to the midline is the interference with pulsatile CSF resorption [22] DCs being "too big" are reported to interfere with the CSF flow and the occurrence of post-DC hydrocephalus signs are described in $88 \%$ of such cases [23]. In our cohort, the exposure of SSS was not accompanied with elevated level of shunt-dependency.

The discrepancies between the incidences of hydrocephalus already reported by other authors (TBI-24\% [24], CI-29\% [25], ICH-15-20\% [26], SAB-20-35\% [27]) and the incidence in our cohort may be caused by the fact that patients with radiologically presented signs of hydrocephalus who did not underwent the shunt implantation were not considered to have a shunt-dependent CSF circulation disturbance. The shunt-dependency in our cohort was; TBI $-8.2 \%, \mathrm{CI}-4 \%, \mathrm{ICH}-8.8 \%, \mathrm{SAB}-25.5 \%$.

\section{Limitations}

The study has several limitations. Data acquisition was retrospective, based on a single-center experience. Furthermore, non-randomized setting left the decision about the DC-size on the attending neurosurgeon. The statements of clinical outcome are limited by heterogeneous cause and seriousness of the underlying diagnosis that lead to the DC [18].

\section{Conclusions}

Complete hemispheric exposure, and therefore larger DC size, seems to be associated with smaller likelihood of shear-bleeding, without the elevation of the incidence of procedure-related complications.

Author contributions MV: study design, data collection and interpretation, manuscript writing. MS, VB, PS and HV: critical revision. CB: statistical evaluation. EG: study design, data interpretation, proofreading, literature search.

Funding Open Access funding enabled and organized by Projekt DEAL. There are no financial conflicts of interest to disclose.

Availability of data and materials Data available on request due to privacy/ethical restrictions.

Code availability Not applicable.

\section{Declarations}

Conflict of interest The authors whose names are listed below certify that they have NO affiliations with or involvement in any organization or entity with any financial or non-financial interest (such as personal or professional relationships, affiliations, knowledge or beliefs) in the subject matter or materials discussed in this manuscript.

Ethical approval Ethik Komission der Rheinische Friedrich-Wilhelms Universität Nr. 427/20.

Consent to participate Not applicable.

Consent for publication Not applicable.

Open Access This article is licensed under a Creative Commons Attribution 4.0 International License, which permits use, sharing, adaptation, distribution and reproduction in any medium or format, as long as you give appropriate credit to the original author(s) and the source, provide a link to the Creative Commons licence, and indicate if changes were made. The images or other third party material in this article are included in the article's Creative Commons licence, unless indicated otherwise in a credit line to the material. If material is not included in the article's Creative Commons licence and your intended use is not permitted by statutory regulation or exceeds the permitted use, you will 
need to obtain permission directly from the copyright holder. To view a copy of this licence, visit http://creativecommons.org/licenses/by/4.0/.

\section{References}

1. Vahedi K, Vicaut E, Mateo J, Kurtz A, Orabi M, Guichard JP, Boutron C, Couvreur G, Rouanet F, Touzé E, Guillon B, Carpentier A, Yelnik A, George B, Payen D, Bousser MG. Sequential-design, multicenter, randomized, controlled trial of early decompressive craniectomy in malignant middle cerebral artery infarction (DECIMAL Trial). Stroke. 2007. https://doi.org/10. 1161/STROKEAHA.107.485235.

2. Cooper DJ, Rosenfeld JV, Murray L, Arabi YM, Davies AR, D’Urso P, Kossmann T, Ponsford J, Seppelt I, Reilly P, Wolfe R. Decompressive craniectomy in diffuse traumatic brain injury. N Engl J Med. 2011. https://doi.org/10.1056/NEJMoa1102077.

3. Güresir E, Schuss P, Vatter H, Raabe A, Seifert V, Beck J. Decompressive craniectomy in subarachnoid hemorrhage. Neurosurg Focus. 2009. https://doi.org/10.3171/2009.3.FOCUS 0954.

4. Fung C, Murek M, Z'Graggen WJ, Krähenbühl AK, Gautschi OP, Schucht P, Gralla J, Schaller K, Arnold M, Fischer U, Mattle HP, Raabe A, Beck J. Decompressive hemicraniectomy in patients with supratentorial intracerebral hemorrhage. Stroke. 2012. https://doi.org/10.1161/STROKEAHA.112.666537.

5. Wagner S, Schnippering H, Aschoff A, Koziol JA, Schwab S, Steiner T. Suboptimum hemicraniectomy as a cause of additional cerebral lesions in patients with malignant infarction of the middle cerebral artery. J Neurosurg. 2001. https://doi.org/10.3171/jns. 2001.94.5.0693.

6. Carney N, Totten AM, O’Reilly C, Ullman JS, Hawryluk GW, Bell MJ, Bratton SL, Chesnut R, Harris OA, Kissoon N, Rubiano AM, Shutter L, Tasker RC, Vavilala MS, Wilberger J, Wright DW, Ghajar J. Guidelines for the management of severe traumatic brain injury. Neurosurgery. 2017. https://doi.org/10.1227/NEU.00000 00000001432.

7. Kurland DB, Khaladj-Ghom A, Stokum JA, Carusillo B, Karimy JK, Gerzanich V, Sahuquillo J, Simard JM. Complications associated with decompressive craniectomy: a systematic review. Neurocrit Care. 2015. https://doi.org/10.1007/s12028-015-0144-7.

8. Flint AC, Manley GT, Gean AD, Hemphill JC, Rosenthal G. Postoperative expansion of hemorrhagic contusions after unilateral decompressive hemicraniectomy in severe traumatic brain injury. J Neurotrauma. 2008. https://doi.org/10.1089/neu.2007.0442.

9. Ho M-Y, Tseng W-L, Xiao F. Estimation of the craniectomy surface area by using postoperative images. Int J Biomed Imaging. 2018. https://doi.org/10.1155/2018/5237693.

10. Güresir E, Vatter H, Schuss P, Oszvald A, Raabe A, Seifert V, Beck J. Rapid closure technique in decompressive craniectomy. J Neurosurg. 2011. https://doi.org/10.3171/2009.12.JNS091065.

11. Hanko M, Soršák J, Snopko P, Opšenák R, Zeleňák K, Kolarovszki B. Incidence and risk factors of early postoperative complications in patients after decompressive craniectomy: a 5-year experience. Eur J Trauma Emerg Surg. 2020. https://doi.org/10.1007/ s00068-020-01367-4.

12. Gao CP, Ang BT. Biomechanical modeling of decompressive craniectomy in traumatic brain injury. Acta Neurochir Suppl. 2008. https://doi.org/10.1007/978-3-211-85578-2_52.

13. Sedney CL, Julien T, Manon J, Wilson A. The effect of craniectomy size on mortality, outcome, and complications after decompressive craniectomy at a rural trauma center. J Neurosci Rural Pract. 2014. https://doi.org/10.4103/0976-3147.133555.
14. Jiang JY, Xu W, Li WP, Xu WH, Zhang J, Bao YH, Ying YH, Luo QZ. Efficacy of standard trauma craniectomy for refractory intracranial hypertension with severe traumatic brain injury: a multicenter, prospective, randomized controlled study. J Neurotrauma. 2005. https://doi.org/10.1089/neu.2005.22.623.

15. De Bonis P, Pompucci A, Mangiola A, Rigante L, Anile C. Posttraumatic hydrocephalus after decompressive craniectomy: an underestimated risk factor. J Neurotrauma. 2010. https://doi.org/ 10.1089/neu.2010.1425.

16. Sturiale CL, De Bonis P, Rigante L, Calandrelli R, D'Arrigo S, Pompucci A, Mangiola A, D'Apolito G, Colosimo C, Anile C. Do traumatic brain contusions increase in size after decompressive craniectomy? J Neurotrauma. 2012. https://doi.org/10.1089/neu. 2012.2556.

17. Reid P, Say I, Shah S, Tolia S, Musku S, Prestigiacomo C, Gandhi CD. Effect of bone flap surface area on outcomes in decompressive hemicraniectomy for traumatic brain injury. World Neurosurg. 2018. https://doi.org/10.1016/j.wneu.2018.08.005.

18. Goedemans T, Verbaan D, Coert BA, Kerklaan BJ, van den Berg R, Coutinho JM, van Middelaar T, Nederkoorn PJ, Vandertop WP, van den Munckhof P. Neurologic outcome after decompressive craniectomy: predictors of outcome in different pathologic conditions. World Neurosurg. 2017. https://doi.org/10.1016/j.wneu. 2017.06.069.

19. Cepeda S, Castaño-León AM, Munarriz PM, Paredes I, Panero I, Eiriz C, Gómez PA, Lagares A. Effect of decompressive craniectomy in the postoperative expansion of traumatic intracerebral hemorrhage: a propensity score-based analysis. J Neurosurg. 2019. https://doi.org/10.3171/2019.2.JNS182025.

20. Fattahian R, Bagheri SR, Sadeghi M. Development of posttraumatic hydrocephalus requiring ventriculoperitoneal shunt after decompressive craniectomy for traumatic brain injury: a systematic review and meta-analysis of retrospective studies. Med Arch. 2018. https://doi.org/10.5455/medarh.2018.72.214-219.

21. Aarabi B, Hesdorffer DC, Ahn ES, Aresco C, Scalea TM, Eisenberg HM. Outcome following decompressive craniectomy for malignant swelling due to severe head injury. J Neurosurg. 2006. https://doi.org/10.3171/jns.2006.104.4.469.

22. Akins PT, Guppy KH. Are hygromas and hydrocephalus after decompressive craniectomy caused by impaired brain pulsatility, cerebrospinal fluid hydrodynamics, and glymphatic drainage? Literature overview and illustrative cases. World Neurosurg. 2019. https://doi.org/10.1016/j.wneu.2019.07.041.

23. Waziri A, Fusco D, Mayer SA, McKhann GM, Connolly ES. Postoperative hydrocephalus in patients undergoing decompressive hemicraniectomy for ischemic or hemorrhagic stroke. Neurosurgery. 2007. https://doi.org/10.1227/01.NEU.0000290894.85072. 37.

24. Yang X-J, Hong G-L, Su S-B, Yang S-Y (2003) Complications induced by decompressive craniectomies after traumatic brain injury. Chin J Traumatol. 2003. PMID: 12659705.

25. Lee MH, Yang JT, Weng HH, Cheng YK, Lin MH, Su CH, Chang CM, Wang TC. Hydrocephalus following decompressive craniectomy for malignant middle cerebral artery infarction. Clin Neurol Neurosurg. 2011. https://doi.org/10.1016/j.clineuro.2011.11.027.

26. Moussa WMM, Khedr W. Decompressive craniectomy and expansive duraplasty with evacuation of hypertensive intracerebral hematoma, a randomized controlled trial. Neurosurg Rev. 2017. https://doi.org/10.1007/s10143-016-0743-6.

27. Yamada S, Nakase H, Park Y-S, Nishimura F, Nakagawa I. Discriminant analysis prediction of the need for ventriculoperitoneal shunt after subarachnoid hemorrhage. J Stroke Cerebrovasc Dis. 2012. https://doi.org/10.1016/j.jstrokecerebrovasdis.2010.11.01. 